\title{
Microscopia confocal in vivo nos depósitos corneanos por amiodarona
}

\author{
In vivo confocal microscopy in amiodarone corneal deposits
}

\author{
Gustavo Victor ${ }^{1}$ \\ Milton Ruiz Alves ${ }^{2}$ \\ Walton Nosé ${ }^{3}$
}

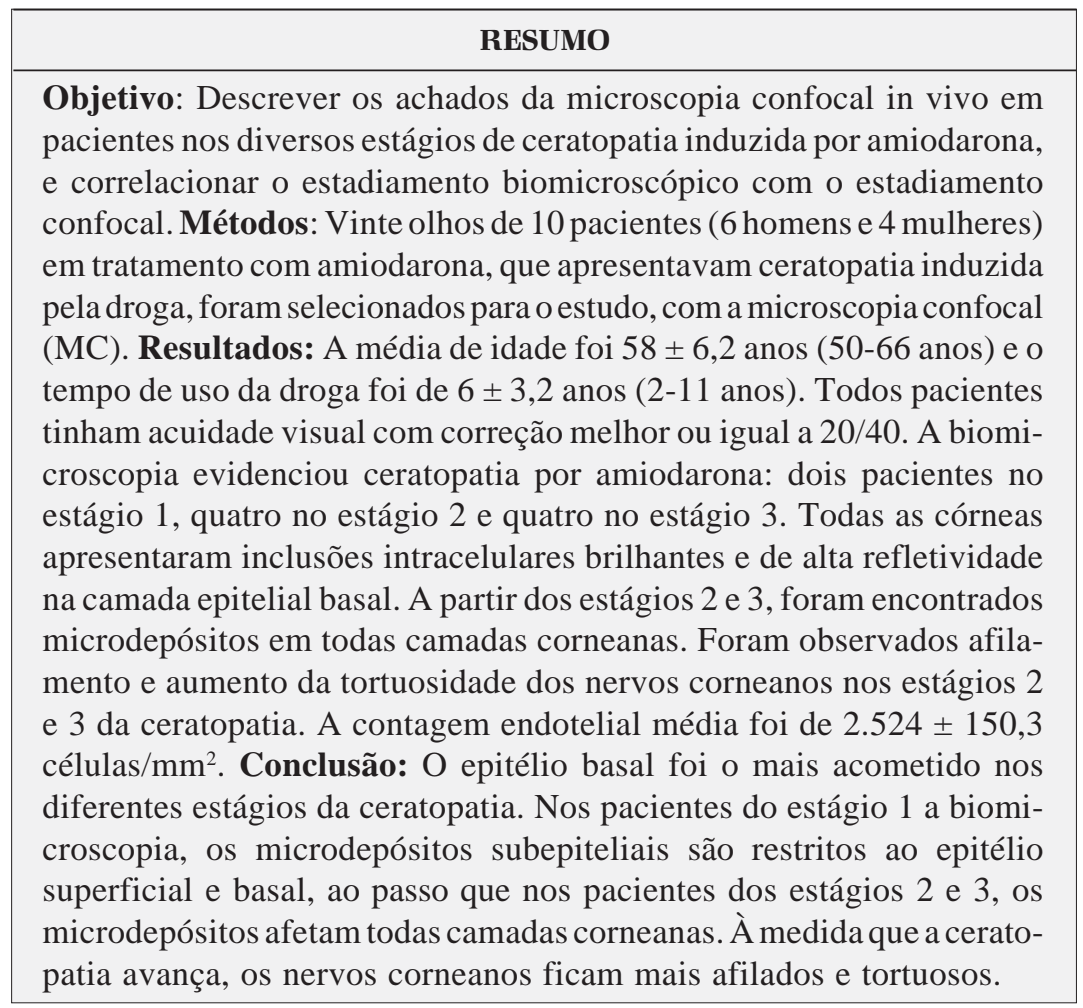

Descritores: Doenças da córnea/induzido quimicamente; Epitélio; Amiodarona/efeitos adversos; Microscopia confocal

Trabalho realizado no Eye Clinic Day Hospital - São Paulo (SP) - Brasil.

${ }^{1}$ Doutor pela Faculdade de Medicina de Ribeirão Preto da Universidade de São Paulo - USP - Ribeirão Preto (SP) - Brasil.

${ }^{2}$ Professor Livre Docente pela USP - São Paulo (SP) Brasil.

${ }^{3}$ Professor Livre Docente pela Universidade Federal de São Paulo - UNIFESP - São Paulo (SP) - Brasil. Professor Titular de Oftalmologia da Universidade Metropolitana de Santos - UNIMES - Santos (SP) - Brasil.

Endereço para correspondência: Gustavo Victor. Av. República do Líbano, 1034 - São Paulo (SP) CEP 04502-001.

E-mail: gustavo.victor@eyeclinic.com.br

Recebido para publicação em 16.04.2006

Última versão recebida em 27.06.2006

Aprovação em 07.07.2006

\begin{abstract}
INTRODUÇÃO
Várias drogas de uso sistêmico ou tópico (ocular) podem causar depósitos corneanos. A amiodarona, um antiarrítmico efetivo no controle de arritmias ventriculares e supraventriculares têm muitos efeitos colaterais documentados como: descoloração da pele, aumento da sensibilidade à luz, hepatite, disfunção tireoideana, fibrose pulmonar, supressão da medula óssea e depósitos corneanos ${ }^{(1)}$. Outros efeitos colaterais oculares relacionados ao nervo óptico, retina, cristalino e pálpebras têm sido descritos ${ }^{(2)}$. A ceratopatia induzida por amiodarona foi primeiramente descrita em $1968^{(3)}$, e definida como depósitos marrom-dourados, arranjados linearmente em formato arboriforme ou de flores (whorl-shaped). Os microdepósitos corneanos são o achado mais comum nos pacientes tratados com amiodarona ${ }^{(2)} \mathrm{e}$, geralmente, são bilaterais e simétricos ${ }^{(4-5)}$. Estes depósitos não alteram a acuidade visual e geralmente desaparecem após 3 a 20 meses de descontinuação da droga ${ }^{(6-7)}$. A prevalência desta ceratopatia varia entre 70 e $100 \%{ }^{(2)}$, mas apenas $10 \%$ dos
\end{abstract}


pacientes reclamam de sintomas $^{(8)}$, como halos coloridos ao redor de luzes em ambientes escuros, quando a pupila está em midríase. O estadiamento, baseado na disposição dos microdepósitos, observável à biomicroscopia, é comumente usado para descrever o grau de comprometimento ${ }^{(9-11)}$. Estes microdepósitos foram estudados com microscopia eletrônica, que revelou inclusões intracitoplasmáticas "lysossomo-like", confinado nas células epiteliais basais, anteriormente à camada de Bowman ${ }^{(12)}$.

A microscopia confocal (MC) é uma importante ferramenta no estudo histológico corneano permitindo o estudo de todas as camadas corneanas in vivo. O objetivo deste estudo é descrever os achados da microscopia confocal in vivo em pacientes nos diversos estágios de ceratopatia induzida por amiodarona, assim como correlacionar o estadiamento biomicroscópico com o estadiamento confocal ${ }^{(13-20)}$.

\section{MÉTODOS}

Vinte olhos de 10 pacientes (6 homens e 4 mulheres) em tratamento com amiodarona, que apresentavam ceratopatia induzida pela droga, foram selecionados para o estudo. Os pacientes não tinham história de doença ou cirurgia ocular prévia e não utilizavam outra droga além da amiodarona. Os pacientes realizaram exame oftalmológico completo e MC. O aparelho utilizado foi o ConfoScan 2 (Nidek ${ }^{\circledR}$, EUA), que possibilita o estudo in vivo das camadas corneanas ${ }^{(13-20)}$. Na classificação biomicroscópica ${ }^{(9-11)}$, o primeiro estágio corresponde a uma coalescência de microdepósitos acinzentados ou marrom-dourados no epitélio basal, dispostos horizontalmente na região inferior da córnea. O segundo estágio, uma arborização adicional e linhas horizontais lembram os fios ou barba de gato. O terceiro estágio é caracterizado pela extensão das lesões assumindo um padrão verticillata "whorl-like", que pode envolver o eixo visual.

\section{RESULTADOS}

\section{Achados clínicos}

A média de idade foi $58 \pm 6,2$ anos (50-66 anos) e o tempo de uso da droga foi de $6 \pm 3,2$ anos (2-11 anos). A dose variou de 100 a $600 \mathrm{mg}$ por dia. Todos pacientes tinham acuidade visual $\log$ MAR com a correção melhor ou igual a 0.30. A pressão intra-ocular média foi de $15 \pm 3,2 \mathrm{mmHg}$. O exame fundoscópico não mostrou evidências de maculopatia em nenhum dos casos. A biomicroscopia evidenciou ceratopatia por amiodarona: dois pacientes no estágio 1, quatro no estágio 2 e quatro no estágio 3 (Figura 1). Apenas um paciente (estágio 3 ) referiu sintomas: halos, às vezes coloridos, à noite.
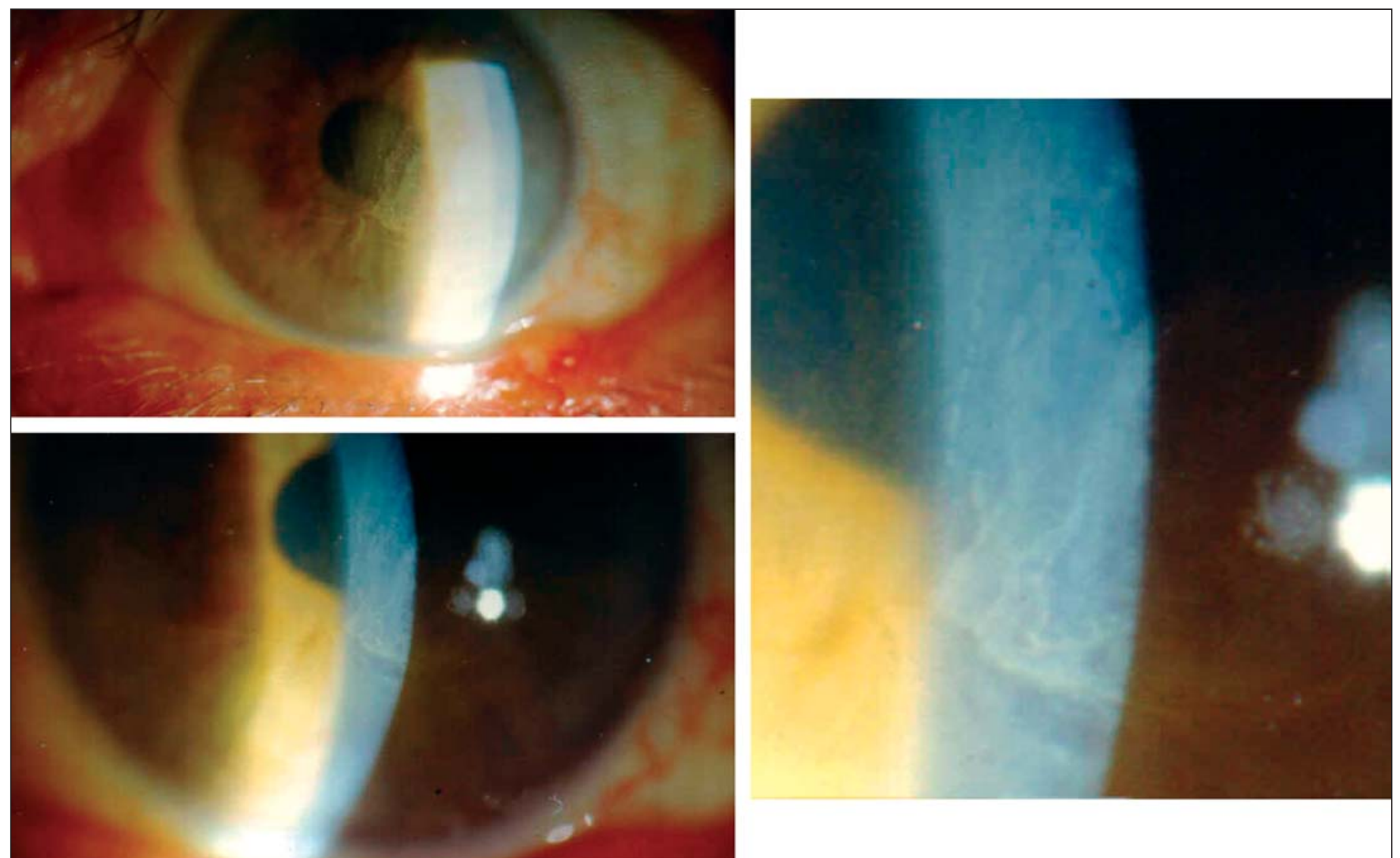

Figura 1 - Depósitos marrom-dourados, subepiteliais, dispostos em linhas horizontais e arborescentes (córnea verticillata) na ceratopatia por amiodarona 


\section{Achados com microscópio confocal}

\section{Nos pacientes no estágio 1:}

O epitélio basal foi o mais afetado (Figura 2). Nesta região, os depósitos caracterizaram-se como inclusões arredondadas, de bordas definidas, brilhantes e de alta refletividade, com diâmetros entre 2 e $15 \mu \mathrm{m}$ de diâmetro. O epitélio superficial apresentou-se de morfologia normal, com áreas de maior refletividade no núcleo e na membrana celular de algumas células (Figura 2). O plexo nervoso subepitelial e assim como os nervos penetrantes do estroma anterior apresentaram-se sem alterações. Da camada de Bowman ao endotélio não foram observadas alterações.

\section{Nos pacientes do estágio 2:}

Os achados microscópicos in vivo no epitélio superficial e basal nos pacientes deste estágio são semelhantes ao do estágio 1. A região da córnea mais afetada foi o epitélio basal. Neste estágio de ceratopatia, foi observado que os microdepósitos se encontravam também na camada de Bowman, circundando o plexo nervoso subepitelial, (Figura 3) e no estroma anterior (Figura 4), transpondo a camada de Bowman. Os nervos do plexo nervoso subepitelial mostraram-se mais tortuosos. No estroma, os microdepósitos se apresentaram com formatos mais irregulares, bordas menos definidas que no epitélio, brilhantes com alta refletividade e medindo entre $2 \mathrm{e}$ $32 \mu \mathrm{m}$ de diâmetro. Nesta região, os microdepósitos estão mais afastados uns dos outros, levando a uma menor densidade de depósitos que no epitélio basal (Figura 4). Foram observados microdepósitos ao redor dos nervos penetrantes no estroma anterior, e afilamento destas estruturas (Figura 5). Nos pacientes em estágio 2 mais avançados, foram observados microdepósitos em todo estroma, com densidade decrescente, e algumas células endoteliais afetadas (Figura 4).
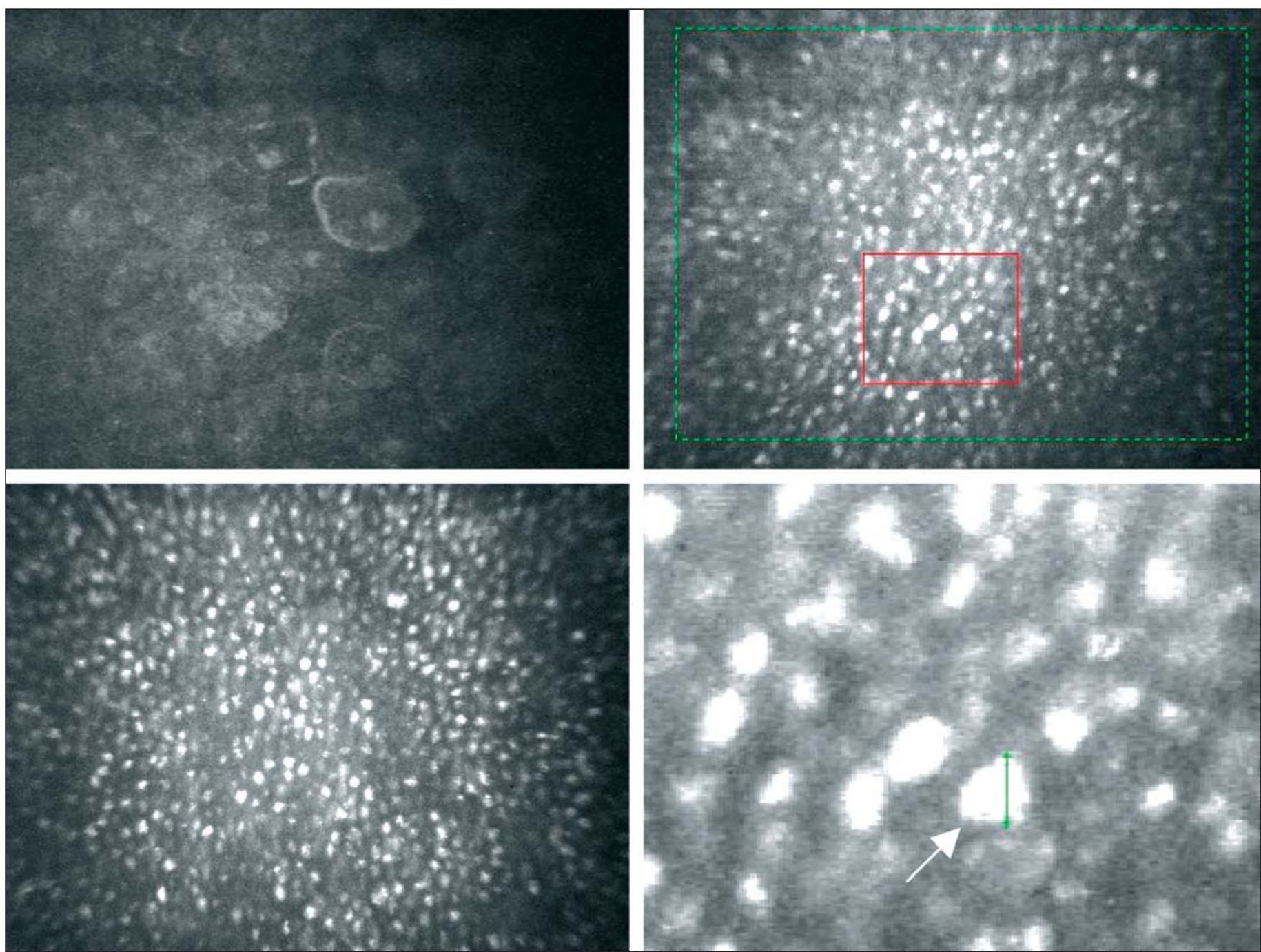

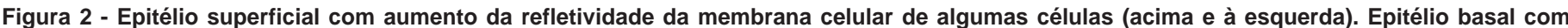

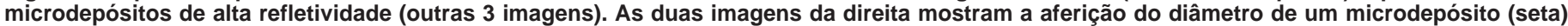
no nível do epitélio basal $(15 \mu \mathrm{m})$. 

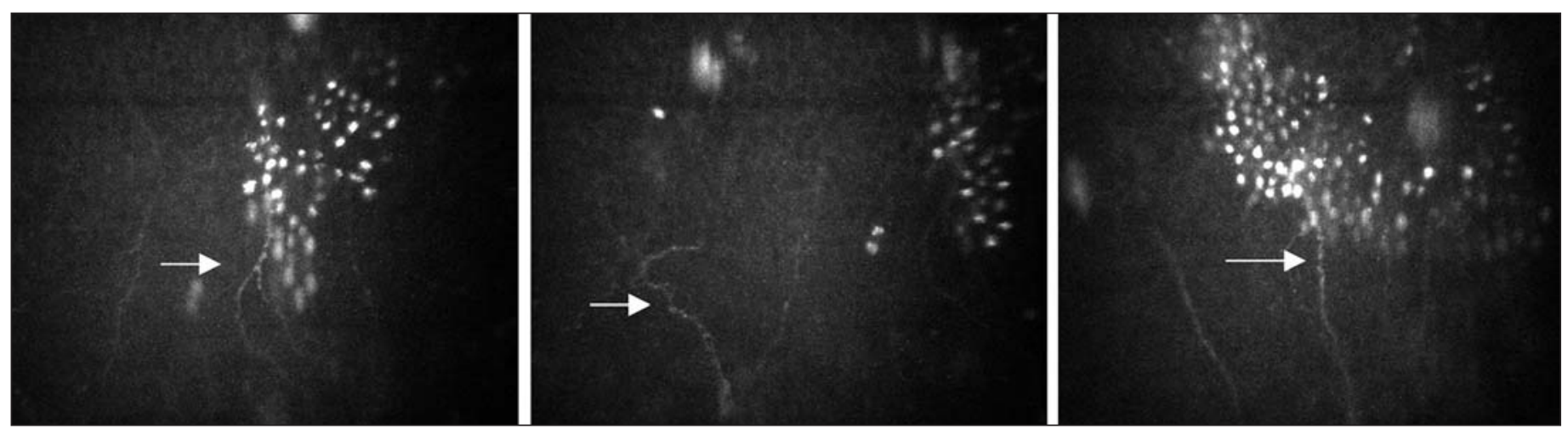

Figura 3 - Nervos do plexo nervoso subepitelial: à esquerda, exame de um paciente no estágio 2 e no meio e à direita, exames de 2 pacientes no estágio 3 da ceratopatia. Note o acúmulo de microdepósitos ao redor dos nervos, o aumento da tortuosidade e o afilamento das fibras nervosas.
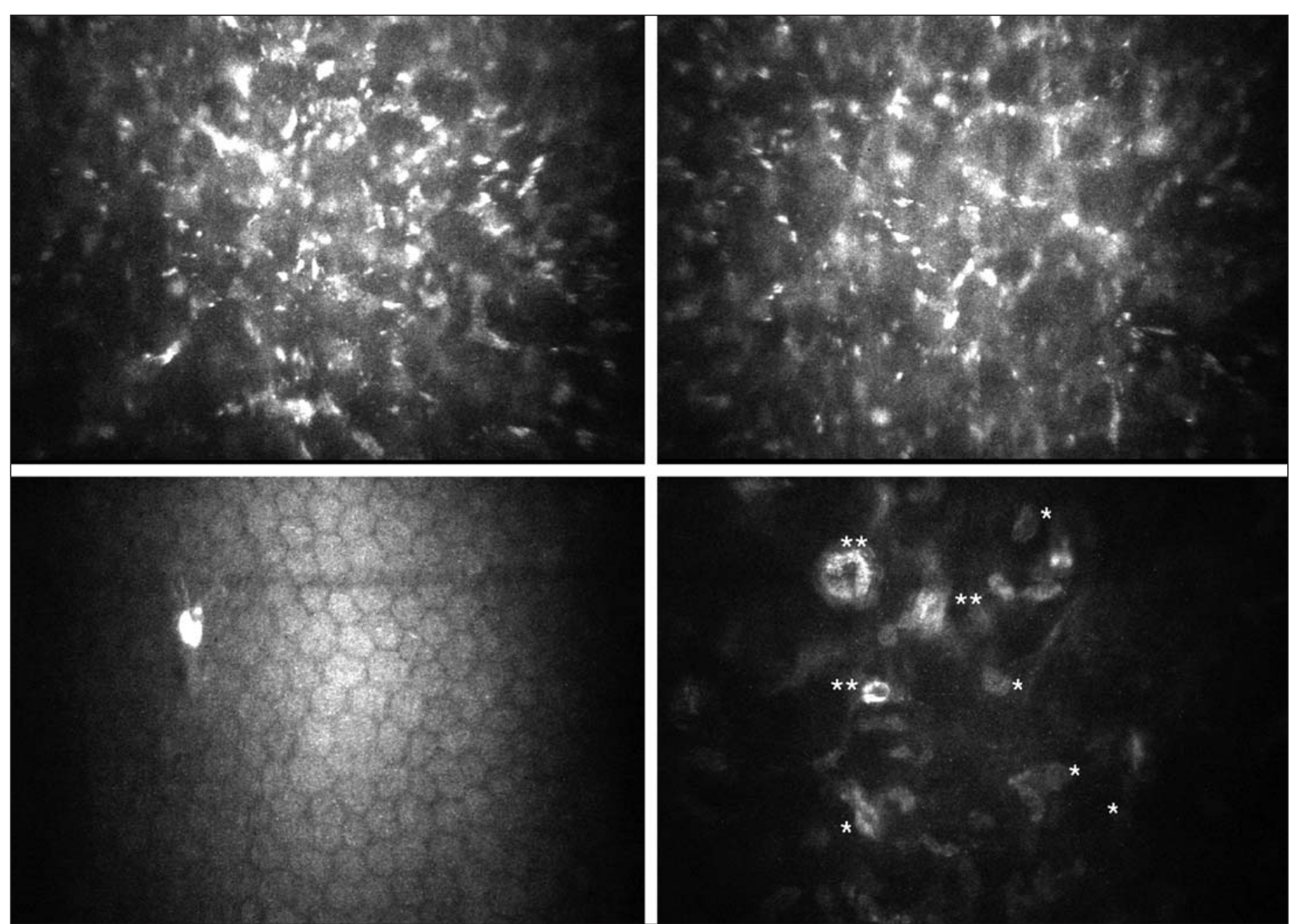

Figura 4 - As fotos superiores mostram os microdepósitos no estroma anterior, em um paciente no estágio 3 (à esquerda) e outro no estágio 2 (à direita). Abaixo e à esquerda podemos observar os microdepósitos no nível endotelial, no mesmo paciente no estágio 3 . Abaixo e à direita podemos observar os microdepósitos e os núcleos dos ceratócitos no estroma profundo do mesmo paciente no estágio 3 . *Núcleo de ceratócitos.

${ }^{\star *}$ Ceratócitos com evidente acometimento.

Nos pacientes do estágio 3:

Neste estágio, a região corneana mais afetada também foi o epitélio basal. Os achados no epitélio superficial, epitélio basal, camada de Bowman, plexo nervoso subepitelial, estroma, nervos penetrantes no estroma anterior e endotélio foram semelhantes aos encontrados nos pacientes no estágio 2, 

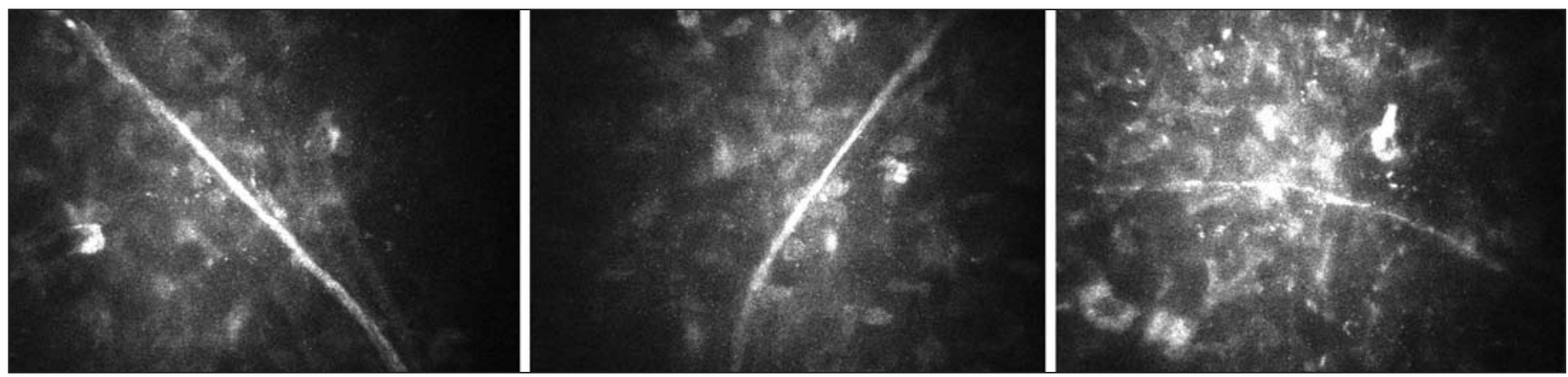

Figura 5 - Nervos penetrantes no estroma anterior. Da esquerda para direita, note o afilamento progressivo das fibras nervosas entre os pacientes no estágio 1 (esquerda), no estágio 2 (meio) e no estagio 3 (direita).

porém em maior intensidade (Figuras 3-5). Há uma maior presença dos microdepósitos em todo estroma e o endotélio também foi mais afetado que no estágio 2. Neste estágio, notou-se afilamento e tortuosidade ainda maior dos nervos corneanos. Em um paciente, no estágio 3 da ceratopatia, foram observadas coalescências maiores no epitélio basal, correspondentes aos achados biomicroscópicos (Figura 6).

A contagem endotelial média foi de $2.524 \pm 150,3$ células $/ \mathrm{mm}^{2}$.

\section{DISCUSS ÃO}

Os depósitos corneanos por amiodarona e seu metabólito ativo, desetilamiodarona, resultam da secreção destes pela glândula lacrimal ${ }^{(8)}$, a qual depende de uma concentração no soro que deve ser alcançada para uma excreção significante pela glândula lacrimal ${ }^{(10)}$. Esta patogênese foi confirmada quando foi observado que pacientes que tinham excessiva produção lacrimal ou usava colírios lubrificantes, diluindo e retirando os depósitos da superfície corneana, desenvolviam baixos graus de microdepósitos, comparado com a dosagem que tomavam da droga. Esta condição é fortemente relacionada à dose diária e duração do tratamento ${ }^{(5,9)}$. Clinicamente, os microdepósitos corneanos são confinados ao epitélio ${ }^{(21)}$, sem nenhum achado anormal observado abaixo da membrana basal. Um estudo com microscopia eletrônica descreveu a presença de corpos membranosos lamelares intracitoplasmáticos "lysosome-like" no epitélio, estroma e endotélio(12).

Empregando a microscopia confocal in vivo, este estudo mostrou que os microdepósitos epiteliais corneanos, que representam inclusões intracitoplasmáticas da amiodarona, semelhantes ao observado à microscopia eletrônica, constituem o achado mais comum da ceratopatia por amiodarona, estando presentes em todos os olhos avaliados. A morfologia do epitélio superficial não se mostrou afetada, como confirmado pela ausência de sinais clínicos correspondentes neste e em outro estudo publicado ${ }^{(22)}$. Porém, observou-se que algumas células do epitélio superficial apresentam áreas de maior refletividade no núcleo e na membrana celular (Figura 2). $\mathrm{O}$ achado mais comum foi a presença de microdepósitos na camada epitelial basal em todos os olhos estudados, semelhantes aos encontra- dos em outro estudo ${ }^{(22)}$ e à microscopia eletrônica ${ }^{(12)}$. Ao examinar todas as camadas corneanas, verificou-se que os microdepósitos intracelulares não estão confinados ao epitélio, aparecendo em todas as camadas corneanas, quanto maior for a ceratopatia induzida. Em outro estudo com $\mathrm{MC}^{(22)}$, foi observado em pacientes com ceratopatia induzida avançada (estágios 2 e 3) microdepósitos e redução significativa da densidade de ceratócitos no estroma anterior, em relação a um grupo controle. Estes depósitos no estroma anterior também foram observados no presente estudo. As alterações observadas nos nervos e endotélio corneanos nos casos avançados são semelhantes a outros estudos ${ }^{(12,22)}$. Entretanto não foi estudada a possível diminuição da sensibilidade corneana nestes pacientes.

\section{CONCLUSÃO}

Observamos os achados da microscopia confocal in vivo nos microdepósitos corneanos da ceratopatia induzida por amiodarona. A observação das estruturas corneanas pela MC nesta ceratopatia induzida mostrou que o epitélio basal é o mais acometido em qualquer estágio da ceratopatia. Nos pacientes do estágio 1 à biomicroscopia, os microdepósitos estão restritos ao epitélio superficial e basal, e nos pacientes do estágio 2 e 3 , os microdepósitos afetam todas camadas corneanas. Quanto maior e mais avançada a ceratopatia induzida, maior o acometimento das camadas corneanas mais profundas. À medida que a ceratopatia avança, os nervos corneanos ficam mais afilados e tortuosos.

\section{ABSTRACT}

Purpose: To describe in vivo confocal microscopy findings in patients with different stages of amiodarone-induced keratopathy, and correlate biomicroscopy stages with confocal stages. Methods: Twenty eyes of 10 patients (6 men and 4 women), who receive treatment with amiodarone were selected for the study with confocal microscopy (MC). Results: The average age was $58 \pm 6.2$ years ( $50-66$ years) and time of use of the drug was $6 \pm 3.2$ years ( $2-11$ years). All patients have best 


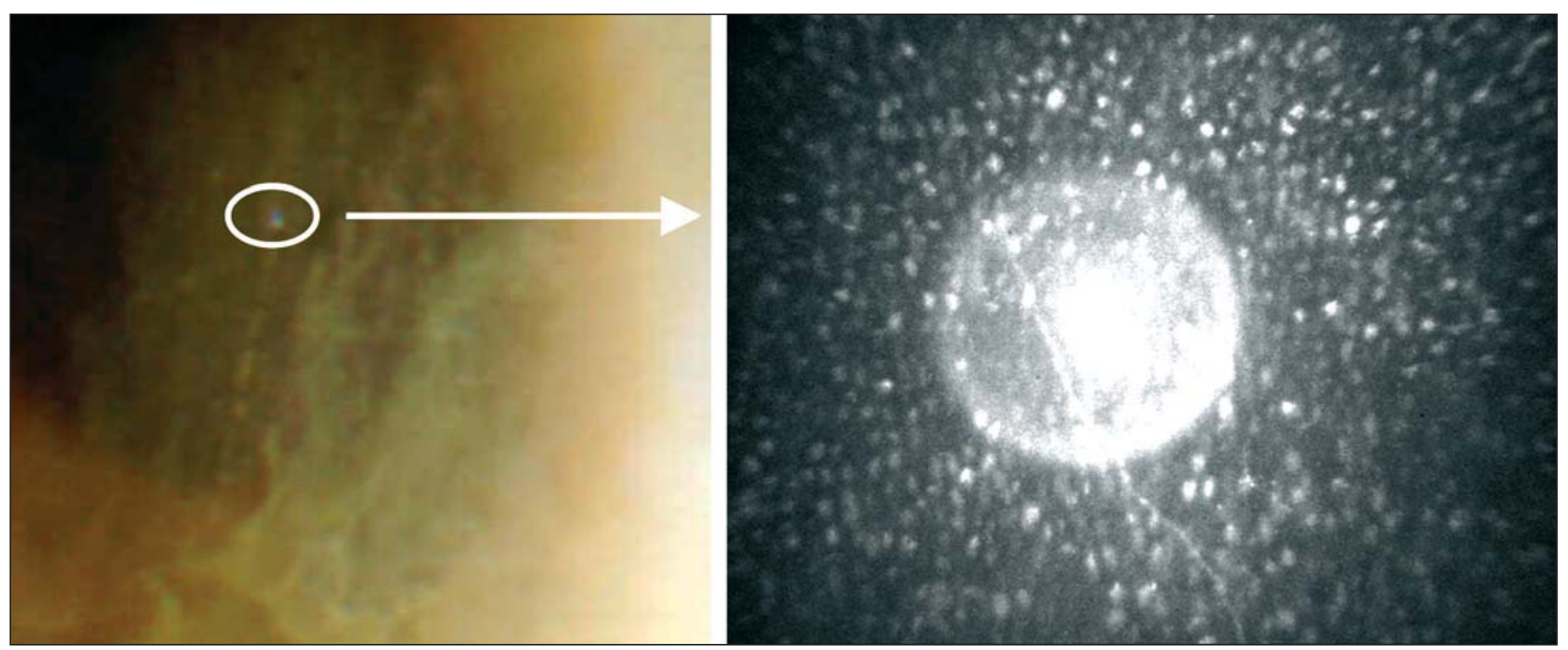

Figura 6 - À esquerda: ceratopatia por amiodarona (verticillata) estágio 3 observada à biomicroscopia. Em destaque área de coalescência dos depósitos. À direita, sua observação à MC, $55 \mu \mathrm{m}$ distante do epitélio superficial.

correct visual acuity $\geq 20 / 40$. There were two patients in stage 1,4 patients in stage 2 and 4 in stage 3 of induced keratopathy. All corneas presented brilliant intracellular inclusions with high reflectivity in the basal epithelium layer. Patients in stage 2 and 3 have all corneal layers affected. There are thinning and increase of tortuosity of corneal nerves in patients in stage 2 and 3. The endothelial count was $2,524 \pm 150,3 \mathrm{cell} / \mathrm{mm}^{2}$. Conclusion: The basal epithelium was most affected in any of the keratopathy stages. In stage 1 patients only the superficial and basal epithelium are affected, while patients in stages 2 and 3 have all corneal layers affected. With the advance of keratophaty the corneal nerves became thinner and tortuous.

Keywords: Corneal diseases/chemically induced; Epithelium/ metabolism; Amiodarone/adverse effects; Microscopy, confocal

\section{REFERÊNCIAS}

1. Burns KE, Piliotis E, Garcia BM, Ferguson KA. Amiodarone pulmonary, neuromuscular and ophthalmological toxicity. Can Respir J. 2000;7(2):193-7.

2. Mantyjarvi M, Tuppurainen K, Ikaheimo K. Ocular side effects of amiodarone. Surv Ophthalmol. 1998;42(4):360-6.

3. Francois J. [Cornea verticillata]. Bull Soc Belge Ophtalmol. 1968;150:65670. French.

4. Davitt SP, Mannis MJ. Delayed development of amiodarone keratopathy in a corneal graft. Cornea. 1997;16(6):695-7.

5. Nielsen CE, Andreasen F, Bjerregaard P. Amiodarone induced cornea verticillata. Acta Ophthalmol (Copenh). 1983;61(3):474-80.

6. Dolan BJ, Flach AJ, Peterson JS. Amiodarone keratopathy and lens opacities. J Am Optom Assoc. 1985;56(6):468-70.
7. Ingram DV, Jaggarao NSV, Chamberlain DA. Ocular changes resulting from therapy with amiodarone. Br J Ophthalmol. 1982;66(10):676-9.

8. Pollak PT. Clinical organ toxicity of antiarrhythmic compounds: ocular and pulmonary manifestations. Am J Cardiol. 1999;84(9A):37R-45R.

9. Kaplan LJ, Cappaert WE. Amiodarone keratopathy. Correlation to dosage and duration. Arch Ophthalmol. 1982;100(4):601-2.

10. Orlando RG, Dangel ME, Schaal SF. Clinical experience and grading of amiodarone keratopathy. Ophthalmology. 1984;91(10):1184-7.

11. Rivera RP, Younge BR, Dyer JA. Atypical amiodarone-induced keratopathy in a patient wearing soft contact lenses. CLAO J. 1989;15(3):219-21.

12. Ghosh M, McCulloch C. Amiodarone-induced ultrastructural changes in human eyes. Can J Ophthalmol. 1984;19(4):178-86.

13. Cavanagh HD, Petroll WM, Alizadeh H, HE Y-G, McCulley JP, Jester JV. Clinical and diagnostic use of in vivo confocal microscopy in patients with corneal diseases. Ophthalmology. 1993;100(10):1444-54.

14. Petroll WM, Jester JV, Cavanagh HD. In vivo confocal imaging: general principles and applications. Scanning. 1994;16(3):131-49.

15. Wiegand W, Thaer AA, Kroll P, Geyer OC, Garcia AJ. Optical sectioning of the cornea with a new confocal in vivo slit-scanning videomicroscope. Ophthalmology. 1995;102(4):568-75.

16. Mustonen RK, McDonald MB, Srivannaboon S, Tan AL, Doubrava MW, Kim CK. Normal human corneal cell populations evaluated by in vivo scanning slit confocal microscopy. Cornea. 1998;17(5):485-92.

17. Victor G, Nosé W. Microscopia confocal in vivo em ceratoconone: relato de caso. Rev Bras Oftalmol. 2001;60(12):853-8.

18. Victor G, Alberti GN, Nosé W. Microscopia confocal in vivo na epitelização da interface após LASIK. Rev Bras Oftalmol. 2002;61(4):284-9.

19. Victor G, Alves MR, Nose W. Avaliação in vivo da histologia corneana após ceratotomia radial com a microscopia confocal. Rev Bras Oftalmol. 2003;62 (9):641-51.

20. Victor G, Campos PJG, Alves MR, Nosé W. Microscopia confocal in vivo na cistinose. Arq Bras Oftalmol. 2004;67(3):553-7.

21. D'Amico DJ, Kenyon KR, Ruskin JN. Amiodarone keratopathy. Drug-induced lipid storage disease. Arch Ophthalmol. 1981;99(2):257-61.

22. Ciancaglini M, Carpineto P, Zuppardi E, Nubile M, Doronzo E, Mastropasqua L. In vivo confocal microscopy of patients with amiodarone-induced keratopathy. Cornea. 2001;20(4):368-73. 